\title{
DEVELOPMENT OF DEVICE BASED ON OPEN-SOURCE ELECTRONICS PLATFORM FOR MONITORING OF CABLE-LOGGING OPERATIONS
}

\author{
Alessandro Lezier, Alberto Cadei, Omar Mologni, Luca Marchi, Stefano Grigolato \\ University of Padova, Italy \\ alessandro.lezier@studenti.unipd.it, alberto.cadei@studenti.unipd.it, omar.mologni@phd.unipd.it, \\ luca.marchi@unipd.it, stefano.grigolato@unipd.it
}

\begin{abstract}
This work presents the development and testing of a prototype based on Arduino® board that aims to collect information on cable-logging operations based on the monitoring of motion and inclination of carriage of a cable logging system. In detail, a GNSS sensor obtains the information of the position, meanwhile an accelerometer combined with a gyroscope registers tilt and vibration information. Type and timing of phases that compose a working cycle are obtained by an automatic procedure. The results are compared with a video acquisition taken as reference. The prototype has partially accomplished the main objective: the work cycle has always been recorded with a high precision, whereas the detection of the timing of operational phases observed some limitations in accuracy.
\end{abstract}

Keywords: forest machines, forest-operations, cable-logging, Arduino® board, precision forestry.

\section{Introduction}

Precision agriculture and precision forestry indicate the use of modern tools and technologies to obtain real-time, non-invasive and accurate information in order to develop decision-making processes, to verify the achievements and the efficiency of the studied process in agriculture and forestry $[1 ; 2]$. The use of precision forestry (PF) in Italy can be classified with reference to five specific areas of application [3]: $i$ ) monitoring and evaluation of forest resources; ii) decision support for forest management; iii) cultivation of wood plantations; $i v$ ) forest uses; $v$ ) traceability of forest products. The application of PF consists of a series of applications ranging from the use of GPS in the operating machines [4], GIS systems are used for the analysis and monitoring of operation planning [5], execution of wood material handling activities such as wood and stand measurement [6] and potentially in the use of sensors for monitoring the behavior of trees subject to external forces [7].

In the context of harvesting systems, the survey of the time necessary to carry out a certain operation is an important activity to evaluate and compare the actual response of the system in terms of productivity. Unfortunately, it is considered a rather expensive procedure because of the number of technicians and researchers needed, even not considering the working time necessary to convert and analyze raw data into usable information. Therefore, it would be preferable to use automatic time survey systems that limit field work and that produce detailed summaries of the performance of machinery or production systems over the long term [4;8;9;10]. Over the past 20 years, forest time measurement techniques have evolved from analog clocks to automatic data collection systems [11]. The most modern techniques for the study of time for the work of machinery use software connected to the machine control system (CAN-BUS system), which allows for precise acquisition of a large number of information [12].

Inspired by previous studies $[13 ; 15]$, conducted to monitor the production process of cable logging systems, the application of a newly developed prototype applied to a carriage moving along a standing skyline cable-logging system is presented. The aim of this work is to automatically detect the number, type and timing of operating phases (e.g., outhaul, inhaul, lateral skidding, etc.) by combining position, vibrations and inclination data of the moving carriage, with a greater accuracy with respect to more traditional time-consuming methods as manual chronometric timing or video-camera assisted timing.

\section{Materials and methods}

The developed prototype consisted of a programmable microcontroller board connected to several sensors able to acquire data on the motion of the carriage. An Arduino ${ }^{\circledR}$ Mega 2560 microcontroller, equipped with an 8 bit processor working at $16 \mathrm{MHz}, 256 \mathrm{~KB}$ of flash memory dedicated to the source code, $8 \mathrm{~KB}$ of RAM and $4 \mathrm{~KB}$ of EEPROM was chosen as the prototyping platform. Arduino MEGA $2560 \circledR$ had 54 pins that could be used as digital inputs or outputs, these worked at a voltage of $5 \mathrm{~V}$ and could supply $20 \mathrm{~mA}$ of current each. To monitor the position and the pitch, and the roll angle of the 
carriage (see Fig. 1), three sensors were connected to the main board: GNSS sensor, gyroscope and accelerometer.

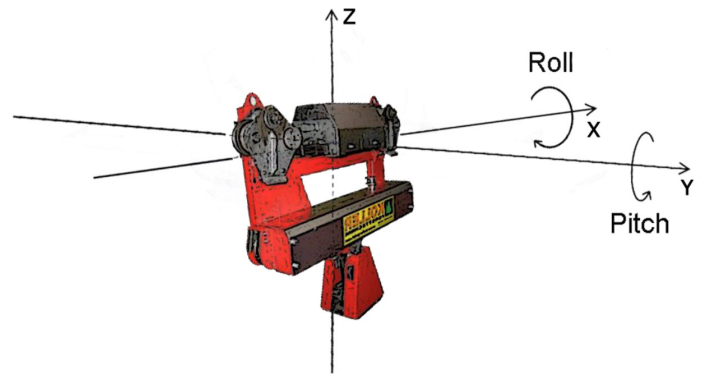

Fig. 1. Pitch and roll of carriage used in cable logging

The GNSS sensor consisted of an Adafruit Ultimate GPS Logger Shield® board that integrated the MTK3329 GPS module with microSD card reader functioning as a datalogger. The device provided, at a frequency rate of $10 \mathrm{~Hz}$, GPS coordinates information in the NMEA 01383 standard as well as the date and time at which the data were collected. Pitch and roll data (Fig. 1) were acquired by coupling a 3-axis Adafruit L3GD20H ${ }^{\circledR}$ gyroscope with a 3-axis Adafruit LIS3DH® accelerometer. The use of two different sensors was needed to correct the drift error that characterizes the gyroscope sensor. More in detail, even if a gyroscope provides an accurate inclination value, the calculation of the inclination based on the gyroscope needs the solution of a continue integral of the angular velocity (i.e. the actual measured value). The approximation based on the sum of a finite sample measured at a constant time leads to drift errors, when the sample recording frequency is lower than the frequency over which the data provided by the sensor change. For this project, a complementary filter was used that solves the problems of both sensors, by simply combining the angular velocity and acceleration data according to Eq. (1):

$$
\alpha_{i}=A \cdot\left(\alpha_{i-1}+\alpha_{i, g y r o} \cdot \partial t\right)+B \cdot\left(\alpha_{i, a c c}\right),
$$

where $\alpha_{i}$-actual tilt angle at $i^{\text {th }}$ cycle;

$\alpha_{i-1}-$ tilt angle calculated at $\left(i_{-1}\right)^{\text {th }}$ cycle;

$\alpha_{g y r o}, \alpha_{a c c}-$ data acquired from the gyroscope and accelerometer respectively;

$A, B$ - constant values equal to 0.9 and 0.1 respectively.

The sampling frequency of the two sensors was set to $100 \mathrm{~Hz}$ in order to reduce the aforementioned drift issue even more, and to bypass the sampling of vibrations induced by engines of motorized carriages, which are generally characterized by higher frequencies. The full set of electronic boards and sensors, a control panel, and a power supply able to guarantee more than 30 hours of recording were installed in a PVC box with dimensions of 20x15x8 cm. The box was modified and equipped with a front water-proof door for access to the control panel and check of the different notification led (see Fig. 2a). Finally, four magnets, hook-and-loop fastener strips and reinforced tape were used to secure it to the moving carriage (see Fig. 2b).

a)

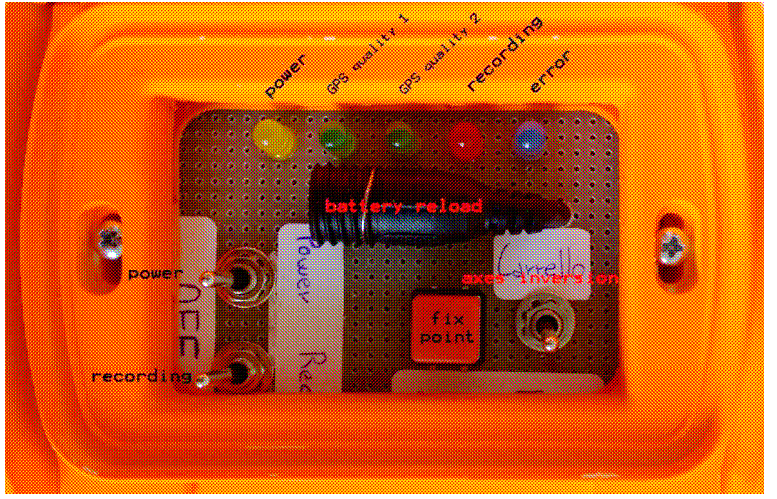

b)

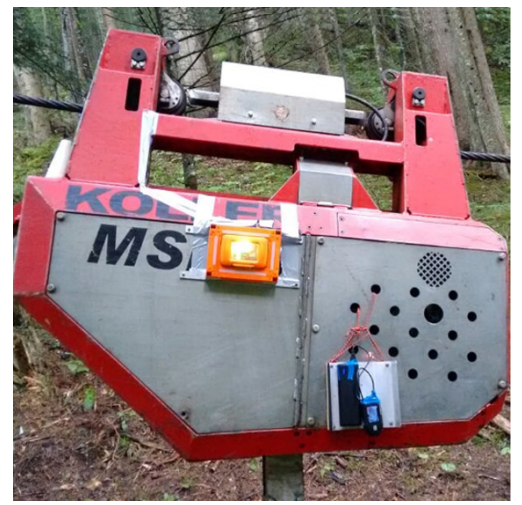

Fig. 2. View of prototype main panel (a) and application to carriage (b) 
The prototype was tested on a multi-span standing skyline cable line constituted by three subsequent spans measuring 76.2, 154.0 and $82.8 \mathrm{~m}$, and installed on a sloped terrain (49\% average value). The extraction direction was downhill and a track-based mobile tower yarder was exploited with an automatic - haulback line slack-pulling carriage. A comprehensive survey of the area was carried out prior to the test. Points of interest have been detected with a GPS (Garmin 62CS®), such as the position of the yarders, of the skyline anchors and intermediate supports. Furthermore, with the help of a LaserTech TruPulse 360® laser range finder the linear distances and the difference in the height between the points of interest were measured. In detail, errors of the GPS position were evaluated by comparing the output coordinates given by the GPS and the data collected during the survey of the line and elaborated by means of the software QGIS®.

Data of the position and values of the pitch and roll angles were obtained from a dedicated software, developed in the general-purpose programming language $\mathrm{C}++$, and loaded into the Arduino platform. An acquisition frequency of $5 \mathrm{~Hz}$ was chosen to faithfully describe the motion of the carriages throughout the entire days of work, maintaining a sufficiently precise dataset able to represent the actual mechanical response of the carriage, without leading to inefficient and excessively expensive output files. Post-processing of data was carried out via software realized in Excel framework, which compared the carriage position (by GPS) with the tilt data (by accelerometer and gyroscope) to automatically detect the different working phases. Five different working phases similarly to [15] could be identified by specifying the ending of each phase as follows:

1. Outhaul Empty: carriage reaches the maximum distance from the yarding point and the inclinometer finishes recording vibrations;

2. Lateral-out and Hookup: inclinometer starts measuring the roll rotation of the carriage due to the lateral skidding;

3. Lateral-in: carriage returns in vertical position and the distance from the yarding point starts to decrease.

4. Inhaul: carriage reaches the minimum distance from the yarding point and the inclinometer finishes recording vibrations.

5. Unload: carriage distance starts to increase and the start of recording vibrations.

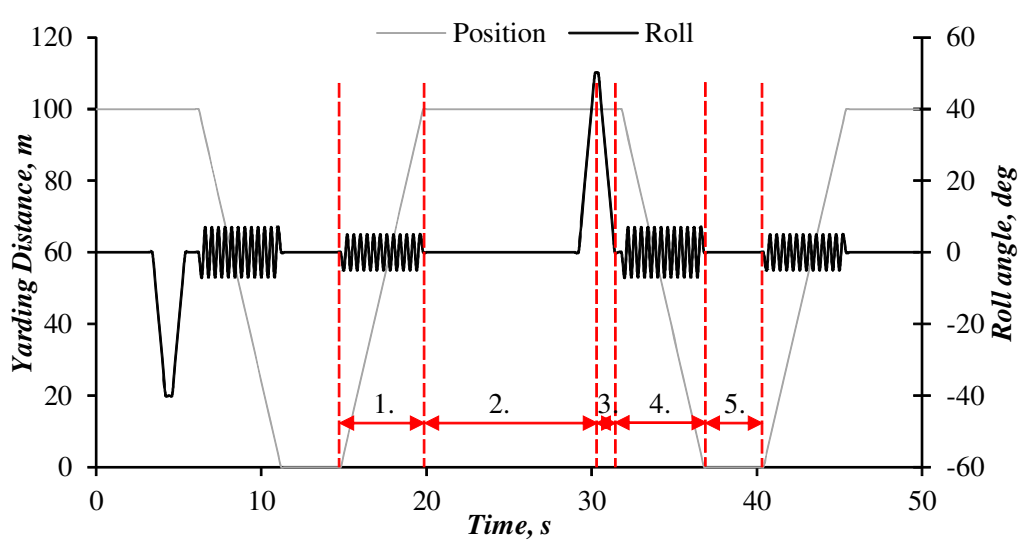

Fig. 3. Detection of phases according to proposed scheme

\section{Results and discussion}

During the whole survey a total of 33 working cycles and 215 different working phases were monitored. Superimposition of the tilt angle and location of the carriage allowed to obtain the qualitative definition of the working cycles depicted in Fig. 5.

Errors on timing and definition of the working phase were evaluated by a direct comparison with two traditional methods. The first solution involved two operators, communicating via radio, which used a traditional timing table to manually define each working phase. The second solution - assumed as reference - was provided by a video camera installed on the carriage and by post-processing the recorded videos it was possible to define with a high accuracy the time limits of each phase.

The comparison in terms of the working cycle was very positive. The IMU-GNSS sensor identified all the work cycles obtaining an average cycle time of $7 \mathrm{~m} 18 \mathrm{~s}(438 \mathrm{~s})$, as reported in Table 1. 
Maximum error of $51 \mathrm{~s}$ was computed for a cycle of $20 \mathrm{~m} 26 \mathrm{~s}(4.01 \%)$. Maximum relative error of $5.14 \%$ was evidenced on a $5 \mathrm{~m} 51 \mathrm{~s}$ cycle. Nevertheless, the obtained average magnitude of errors is comparable to the manual chronometric system (Table 1).

Table 1

Timing of the working cycles

\begin{tabular}{|c|c|c|c|c|c|c|c|}
\hline \multirow{2}{*}{ Statistics } & Camera Time & \multicolumn{3}{|c|}{ GPS Time } & \multicolumn{3}{c|}{ Chrono Time } \\
\cline { 2 - 8 } & Time, $\mathbf{s}$ & Time, $\mathbf{s}$ & Error, $\mathbf{s}$ & Error, \% & Time, s & Error, s & Error, \% \\
\hline Min & 212 & 214 & 0 & $0.0 \%$ & 0 & 0 & $0.0 \%$ \\
\hline Max & 1226 & 1277 & 51 & $5.1 \%$ & 51 & 32 & $6.0 \%$ \\
\hline Mean & 438 & 439 & 7 & $1.4 \%$ & 7 & 7 & $1.5 \%$ \\
\hline Dev.st & 209 & 216 & 10 & $1.4 \%$ & 10 & 7 & $1.4 \%$ \\
\hline
\end{tabular}

A qualitative definition of the working phases was then detected with post-processing of the IMUGNSS sensor data (Fig. 4). Analysing the figure, it clearly emerges the changes of the roll angles during specific change of phases, e.g., Unload to Unhaul and Hook to Lateral-in. On the contrary, the change from Lateral-in to Inhaul and Outhaul to Hook was at times less evident. This is due to the fact that the magnitude of the carriage speed and pitch/roll angles do not show specific "characterizing" ranges with these two particular phases as initially hypothesized (Table 2).

Table 2

Timing and carriage motion data of the working cycles

\begin{tabular}{|c|c|c|c|c|c|c|c|c|c|c|c|}
\hline \multirow{2}{*}{ 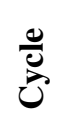 } & \multirow{2}{*}{ Statistics } & \multirow{2}{*}{$\begin{array}{l}\text { Camera } \\
\text { Time, } s\end{array}$} & \multicolumn{3}{|c|}{ Chrono } & \multicolumn{3}{|c|}{ IMU-GNSS } & \multirow{2}{*}{$\frac{\text { Speed }}{\mathrm{km} \cdot \mathrm{h}^{-1}}$} & \multirow{2}{*}{$\begin{array}{l}\text { Pitch } \\
\text { deg }\end{array}$} & \multirow{2}{*}{$\frac{\text { Roll }}{\text { deg }}$} \\
\hline & & & Time, $s$ & Error, $\mathrm{s}$ & Error, \% & Time, $s$ & Error, $\mathbf{s}$ & Error, \% & & & \\
\hline \multirow{4}{*}{ כू } & Min & 55 & 37 & 0 & $0.0 \%$ & 49 & 0 & $0.3 \%$ & 0.00 & -43.0 & -32.0 \\
\hline & Max & 99 & 100 & 27 & $30.0 \%$ & 96 & 37 & $39.4 \%$ & 10.05 & 4.2 & 22.4 \\
\hline & Mean & 68 & 73 & 5 & $6.8 \%$ & 70 & 13 & $17.7 \%$ & 2.87 & -22.1 & 0.6 \\
\hline & Dev. St. & 11 & 14 & 7 & $8.3 \%$ & 13 & 10 & $11.7 \%$ & 2.50 & 5.3 & 4.9 \\
\hline \multirow{4}{*}{ 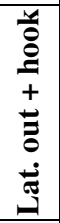 } & Min & 0 & 0 & 0 & $0.0 \%$ & 9 & 0 & $0.2 \%$ & 0.00 & -39.2 & -69.3 \\
\hline & Max & 176 & 160 & 24 & $34.8 \%$ & 129 & 41 & $50.0 \%$ & 8.86 & -7.1 & 16.1 \\
\hline & Mean & 81 & 82 & 8 & $9.4 \%$ & 44 & 18 & $19.6 \%$ & 1.43 & -25.4 & 0.2 \\
\hline & Dev. St. & 45 & 38 & 8 & $10.6 \%$ & 31 & 12 & $13.8 \%$ & 2.10 & 1.3 & 5.3 \\
\hline \multirow{4}{*}{ 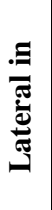 } & Min & 0 & 0 & 0 & $0.0 \%$ & 9 & 0 & $0.3 \%$ & 0.00 & -46.3 & -68.9 \\
\hline & Max & 432 & 425 & 30 & $22.2 \%$ & 435 & 57 & $71.4 \%$ & 6.12 & -2.7 & 58.8 \\
\hline & Mean & 98 & 101 & 5 & $3.9 \%$ & 99 & 18 & $17.8 \%$ & 0.77 & -25.1 & -9.0 \\
\hline & Dev. St. & 109 & 113 & 8 & $6.1 \%$ & 110 & 16 & $19.4 \%$ & 1.19 & 1.9 & 19.7 \\
\hline \multirow{4}{*}{ 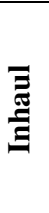 } & Min & 68 & 51 & 0 & $0.0 \%$ & 71 & 1 & $0.9 \%$ & 0.00 & -46.9 & -31.0 \\
\hline & Max & 312 & 268 & 8 & $10.4 \%$ & 308 & 69 & $94.8 \%$ & 5.63 & 5.1 & 27.0 \\
\hline & Mean & 106 & 90 & 3 & $2.9 \%$ & 105 & 26 & $36.1 \%$ & 1.78 & -22.6 & -1.2 \\
\hline & Dev. St. & 40 & 38 & 3 & $3.2 \%$ & 40 & 18 & $25.4 \%$ & 1.56 & 5.3 & 6.4 \\
\hline \multirow{4}{*}{$\frac{\bar{\pi}}{5}$} & Min & 0 & 0 & 0 & $0.0 \%$ & 4 & 0 & $0.0 \%$ & 0.00 & -48.1 & -22.7 \\
\hline & Max & 59 & 84 & 5 & $27.3 \%$ & 59 & 37 & $70.9 \%$ & 5.55 & \begin{tabular}{|l|}
-5.3 \\
\end{tabular} & 23.9 \\
\hline & Mean & 16 & 26 & 1 & $4.8 \%$ & 15 & 15 & $45.7 \%$ & 1.86 & \begin{tabular}{|c|}
-23.9 \\
\end{tabular} & 0.8 \\
\hline & Dev. St. & 14 & 20 & 2 & $9.5 \%$ & 11 & 12 & $19.4 \%$ & 1.26 & 3.6 & 3.3 \\
\hline
\end{tabular}

Therefore, timing of each working phase does not present the same remarkable results obtained for the working cycle analyses (Fig. 6). Table 2 shows that on average a mean error of 17.7, 19.6 and $17.8 \%$ was obtained in the first three phases. A much lower timing precision was evidenced in the detection of the Inhaul and Unload phases. If the timing error exceeds a certain value, the pitch/roll output data - in terms of magnitude only - become not significant. Consequently, it should be 
necessary to improve the phase change detection, for example, by using a more powerful and efficient filter, which takes into account the changes in frequency of the carriage movements. Alternatively a post-processing algorithm that includes the signal analysis might provide clearer results.

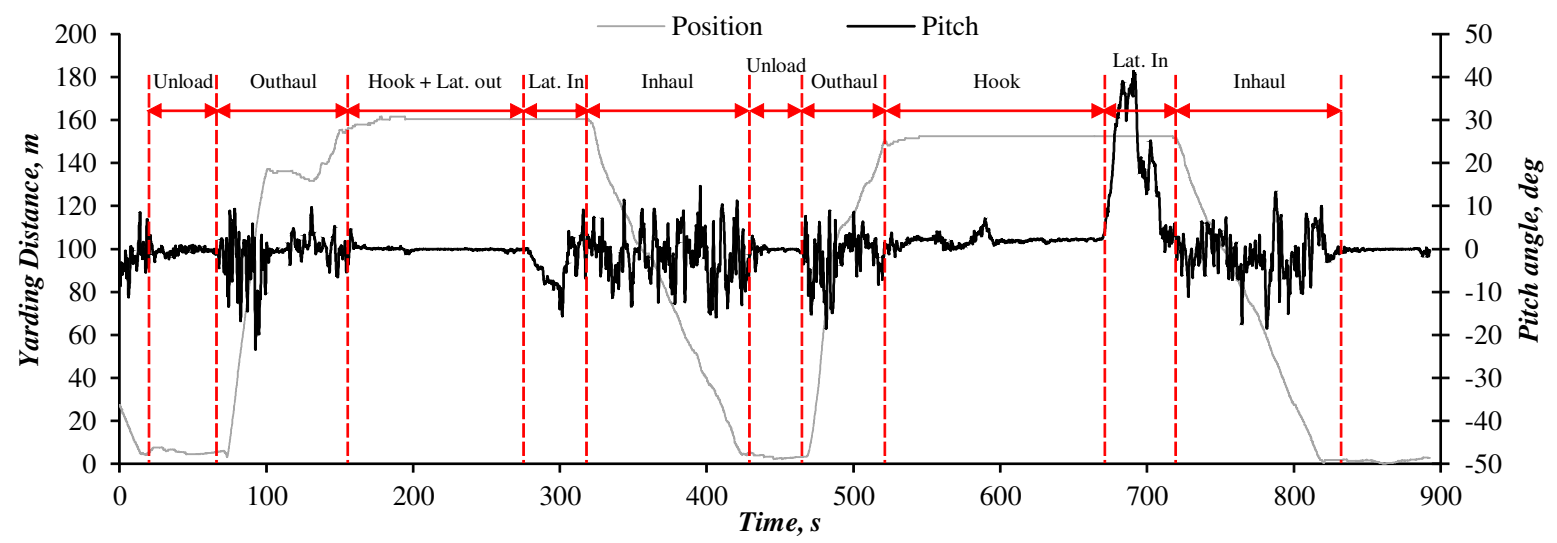

Fig. 4. Sample of single phase detection

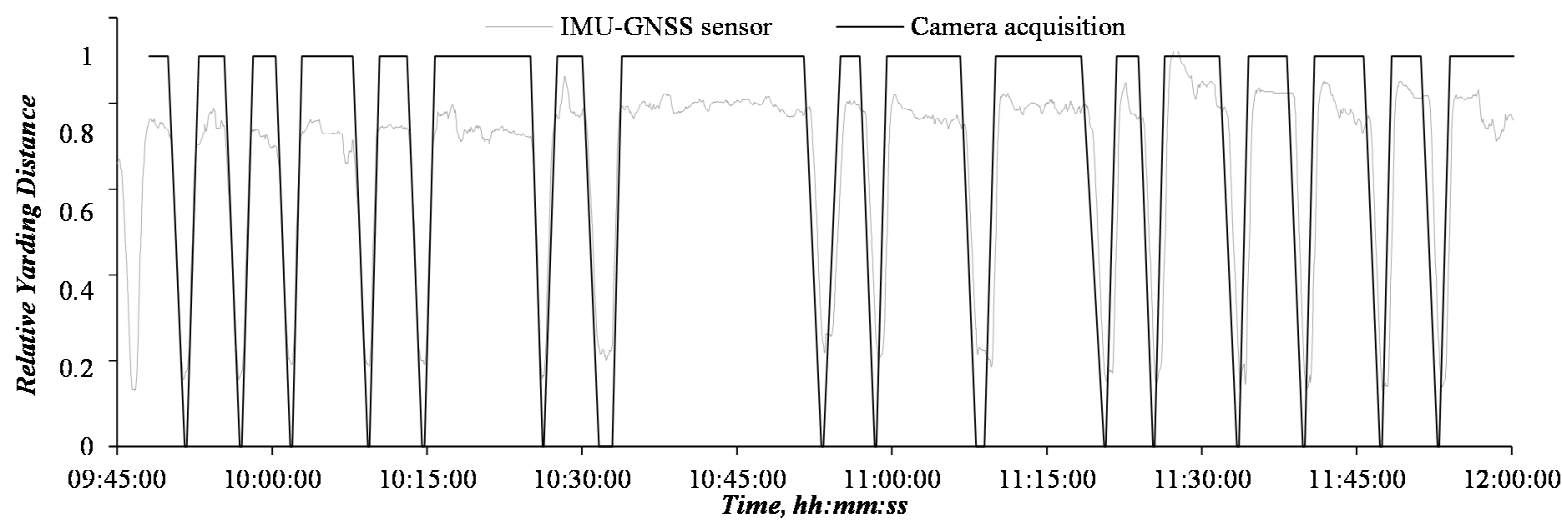

Fig. 5. Sample of working cycle detection
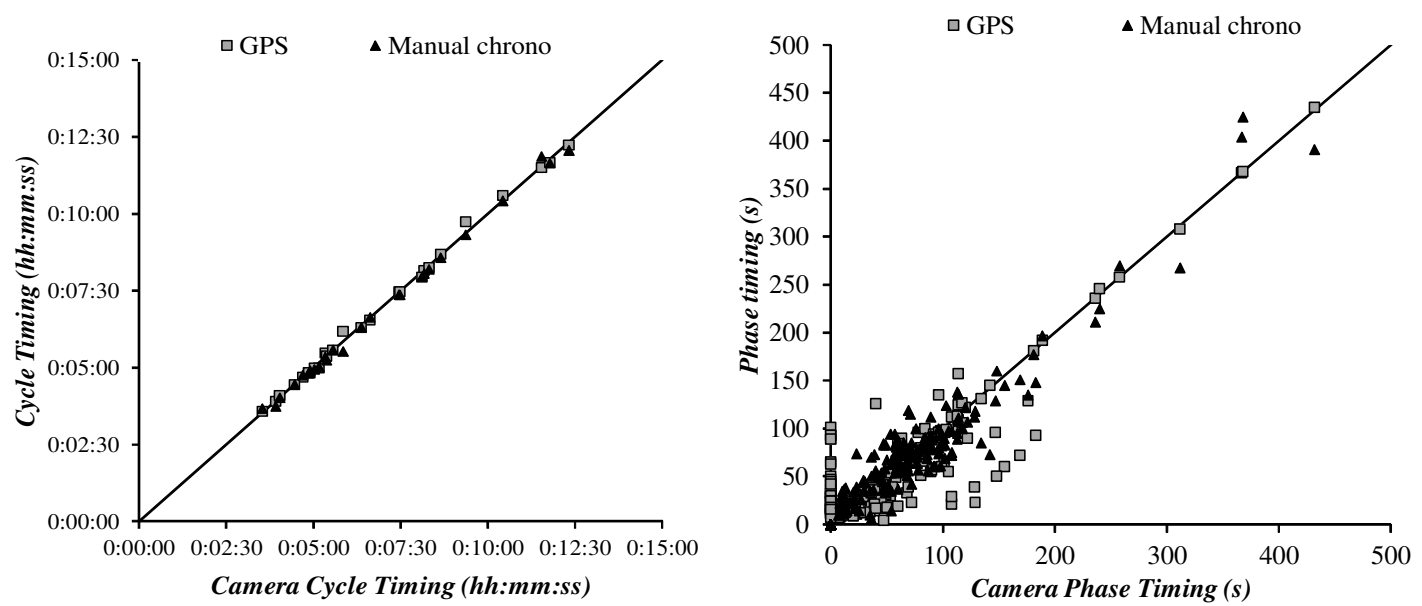

Fig. 6. Comparison of timing calculated with IMU-GNSS sensor and manual chronometric system with respect to camera acquisitions

\section{Conclusions}

The integration of tilt and vibration data in the analysis of the IMU-GNSS sensor outputs provides reliable results in the time-surveying of the working cycles. Some drawbacks still affect the accuracy in the detection of each single phase that compose the complete cycle. If the observed limitations are overcome (e.g., by improving the signal filter or post-processing algorithm), a further development of this prototype could yet provide several advantages in the context of time-surveying of forest 
operations. More in detail, the development of an automatic procedure, to be installed on a laptop or tablet, which reads the input-data collected from the sensor and provides continuous information regarding the efficiency of the cable logging system, could be an important tool to simplify measurements of the cable line productivity and significantly reduce the time-surveying costs.

\section{Acknowledgements}

The research was founded by the Department of Land, Environment, Agriculture and Forestry, Università degli Studi di Padova under the Grant BIRD 2017 "SLOPE: tree stability in cable logging and safety of operators - Development of an alert system based on wireless and low cost sensors".

\section{References}

[1] Blasi G., Pisante M., Sartori L., Casa R., Liberatori S., Loreto F., De Bernardinis B. Linee guida per lo sviluppo dell' agricoltura di precisione in Italia. Rome, ITALY, 2017.

[2] Pezzuolo A., Guarino M., Sartori L. Marinello F. A feasibility study on the use of a structured light depth-camera for three-dimensional body measurements of dairy cows in free-stall barns. Sensors, 2, 2018, $673 \mathrm{p}$.

[3] Corona P., Chianucci F., Quatrini V., Civitarese V., Clementel F., Costa C., ... Scrinzi G. Precision forestry: concepts, tools and perspectives in Italy. Forest@ - Rivista Di Selvicoltura Ed Ecologia Forestale, 14(1), 2017, pp. 124-134.

[4] McDonald T. P., Fulton J. P. Automated time study of skidders using global positioning system data. Computers and Electronics in Agriculture, 48(1), 2005, pp. 19-37.

[5] Grigolato S., Mologni O., Cavalli R. GIS Applications in Forest Operations and Road Network Planning: an Overview over the Last Two Decades. Croatian Journal of Forest Engineering, 38, 2017, pp. 175-186.

[6] Costa C., Figorilli S., Proto A. R., Colle G., Sperandio G., Gallo P., Antonucci F., Pallottino F. Menesatti P. Digital stereovision system for dendrometry, georeferencing and data management. Biosystems Engineering, 174, 2018, pp. 126-133.

[7] Marchi L., Grigolato S., Mologni O., Scotta R., Cavalli R. Montecchio L. State of the art on the use of trees as supports and anchors in forest operations. Forests, 9, 2018, 467 p.

[8] Mologni O., Dyson P., Amishev D., Proto A. R., Zimbalatti G., Cavalli R. Grigolato S. Tension monitoring on large winch-assist forwarders operating in British Columbia. Croatian Journal of Forest Engineering, 39, 2018, pp. 95-105.

[9] Grigolato S., Mologni O., Proto A. R., Zimbalatti G. Cavalli R. Assessment of noise level and noise propagation generated by light-lift helicopters in mountain natural environments. Environmental Monitoring and Assessment, 190, 2018, 88 p.

[10] Grigolato S., Panizza S., Pellegrini M., Ackerman P. Cavalli R. Light-lift helicopter logging operations in the Italian Alps: a preliminary study based on GNSS and a video camera system. Forest Science and Technology, 12(2), 2015, pp. 88-97.

[11] Brewer J., Talbot B., Belbo H., Ackerman P. Ackerman S. A comparison of two methods of data collection for modelling productivity of harvesters: manual time study and follow-up study using on-board-computer stem records. Annals of Forest Research, 61(1), 2018, pp. 109-124.

[12] Nuutinen Y., Väätäinen K., Heinonen J., Asikainen A., Röser D. The accuracy of manually recorded time study data for harvester operation shown via simulator screen. Silva Fennica, 42(1), 2008, pp. 63-72.

[13] Gallo R., Grigolato S., Cavalli R., Mazzetto F. GNSS-based operational monitoring devices for forest logging operation chains. Journal of Agricultural Engineering, 44(2s), 2013, pp. 140-144.

[14] Pierzchała M., Kvaal K., Stampfer K., Talbot B. Automatic recognition of work phases in cable yarding supported by sensor fusion. International Journal of Forest Engineering, 29(1), 2017, pp. 12-20.

[15]Proto A. R., Skoupy A., Macri G. Zimbalatti G. Time consumption and productivity of a medium size mobile tower yarder in downhill and uphill configurations : a case study in Czech Republic. Journal of Agriculture Engineering, 67, 2016, pp. 216-221. 